\title{
Combined Armature and Field Fuzzy Speed Control of a DC Motor for Efficiency Enhancement
}

\author{
Ahmed M. Adday \\ Electrical Eng. Dept. \\ College of Engineering \\ University of Mosul \\ ahmedmhadday@yahoo.com
}

\author{
Dr. Mazin Z .Othman \\ Computer and Information Eng. Dept. \\ College of Electronics Engineering \\ University of Mosul \\ dr.mazin@uomosul.edu.iq
}

\begin{abstract}
This paper presents the design and implementation of fuzzy logic controller (FLC) to improve the efficiency of a separately excited dc motor.The improvement of motor efficiency is achieved by controlling both armature voltage and field voltage simultaneously which are decided by the FLC. DC-DC converters (chopper Buck) are utilized to control armature voltage and field voltage. Design and MATLAB simulation are presented together with implementation of fuzzy logic controller using microcontroller type (MC9S12DP256B).The results show that the efficiency of the DC motor is clearly increased in light and medium load torques in comparison to the armature fuzzy speed controller.
\end{abstract}

Key words: speed control of DC motors, fuzzy control, and efficiency enhancement.

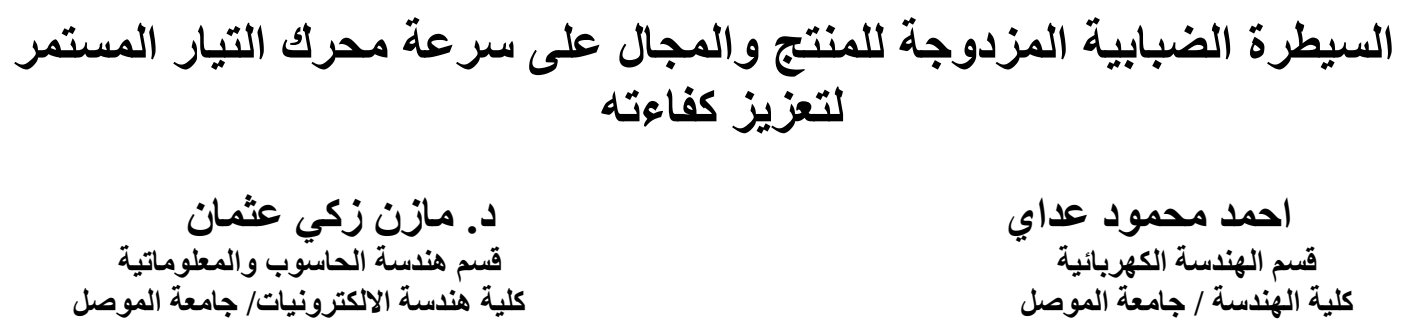

ألخلاصة

تم في هذا البحث تصميم وتنفيذ مسيطر المنطق الضبابي لتحسين كفاءة محرك التيار المستمر ذو الإثارة المنفصلة ووذلك التصائ

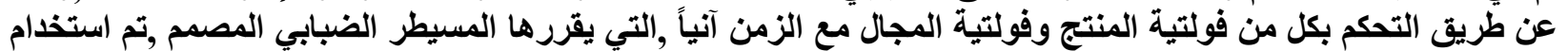

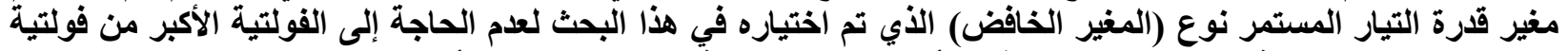

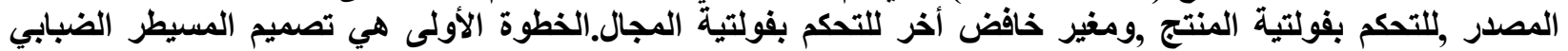

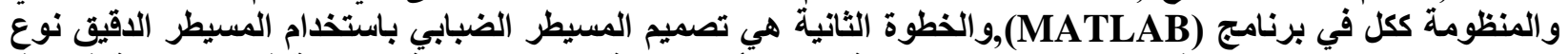

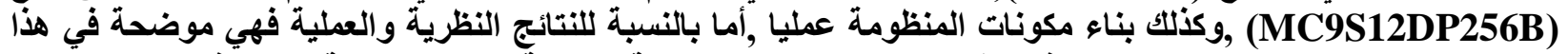
البحث التي تظهر تحسن كفاءة المحرك إذا ما قورنت مع السيطرة الضبابية للسرعة بالتحكم بفولتية المنتج فقط. 


\section{Introduction}

DC motors are used in many applications and industrial fields, because they can provide a high starting torque. It is also possible to obtain speed control over wide range below and above the rated speed. It is well known that the speed of separately excited DC motor can be achieved either by varying the armature voltage (armature control) or the field current (field control). The speed is directly proportional to the armature voltage and inversely proportional to the field current. In armature control, one can get constant reference speed up to rated over the whole load range. However, in the field control, constant reference speed up to $120 \%-130 \%$ rated can be achieved but with loss of the motor developed torque.

Therefore, many researches focused on combining the armature control and field control to get the benefit of both. Egami et al [1] proposed two model reference adaptive control systems (MRACS) for efficiency optimized speed control. The first one was the current ratiotype MRACS in which the optimal ratio of the armature current and field current that yields maximum efficiency was theoretically derived, and MRACS was synthesized by treating the current ratio error as an output variable of the controlled object. The second MRACS was the voltage/current ratio-type MRACS, in which the optimal ratio of field voltage and armature current giving maximum efficiency was theoretically derived as well. Efficiency was considerably improved by these methods at a light load condition.

Kettleborough,J.G. et al [2] used armature control with spillover field weakening, without efficiency enhancement. They followed the following procedure: when the demand speed is below or equal to the base speed, the speed error is eliminated by controlling the armature voltage while keeping the field flux constant at its maximum value. When either the speed demand is greater than the base speed, or the armature voltage for steady-state conditions exceeds an arbitrarily chosen figure of about $90 \%$ of the rated value, the armature voltage is held at this figure while the speed is controlled by varying the field flux. The $10 \%$ reserve of armature voltage is used to ensure a fast response following any sudden load change as the electrical time constant of the armature circuit is much smaller than that of the field circuit.

Gaber S. E.and Yousef H.A. [3] designed a self tuning regulator (S.T.R.) based on the indirect adaptive pole-placement technique in order to improve the efficiency of an adjustable speed dc motor drive system under a wide range of operating conditions.

El-sattar et al [4] presented a systematic design method for efficiency-optimized speed control system synthesis based on the improved optimal regulator theory. For a separately excited dc motor system the ratio of the armature current and the field current that gives the maximum efficiency was analytically derived. They concluded that an efficiency improvement was achieved specially at light load.

On the other hand, the use of fuzzy logic theory in designing speed controller requires, however, the knowledge of human expert to create an algorithm that agrees with human expertise and thinking [5]. Recently, many papers were published that involved in demonstrating the power of the FLC as a decision making in designing different electrical drives (see for example [6], [7], [8], and [9]).

In this paper, Fuzzy Logic Controller is used as an intelligent control method to decide how much the DC motor relies on the armature circuit or on the field circuit to produce the required speed. The FLC decision should be valid for the whole range of the load torque in a way that increases the motor efficiency. 


\section{Mathematical Model of the Separately Excited Dc Motor:}

In this section the main equations of the dc motor will be explained, It is needed to know the main relationship between armature voltage, field voltage, speed of motor, and developed torque. Figure (1) shows the equivalent circuit of a separately excited DC motor.

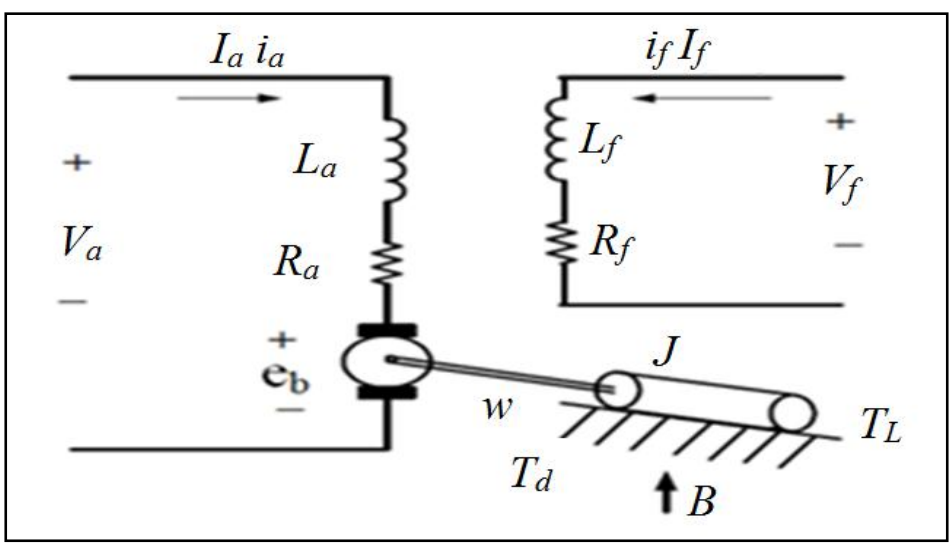

Fig. 1. Equivalent circuit of a separately excited dc motor

$V_{a}(t)=R_{a} i_{a}(t)+L_{a} \frac{d i_{a}(t)}{d t}+e_{b}$

$V_{f}(t)=R_{f} i_{f}(t)+L_{f} \frac{d i_{f}(t)}{d t}$

$e_{b}=K_{e} \omega_{r}$

$K_{E}=L_{a f} i_{f}(t)$

$T_{e}(t)=K_{E} i_{a}(t)$

Efficiency $=\frac{P_{\text {out }}}{P_{\text {in }}} * 100 \%$

$\mathrm{Pin}=\mathrm{Pa}+\mathrm{Pf}$

$\mathrm{P}_{\mathrm{a}}=\mathrm{V}_{\mathrm{a}} \mathrm{I}_{\mathrm{a}}$

$\mathrm{P}_{\mathrm{f}}=\mathrm{V}_{\mathrm{f}} \mathrm{I}_{\mathrm{f}}$

$\mathrm{P}_{\text {out }}=\mathrm{T}_{\text {sh }} \mathrm{W}_{\mathrm{r}}$

Efficiency $=\frac{\mathrm{T}_{\mathrm{sh}} \mathrm{w}_{\mathrm{r}}}{\mathrm{V}_{\mathrm{f}} \mathrm{I}_{\mathrm{f}}+\mathrm{V}_{\mathrm{a}} \mathrm{I}_{\mathrm{a}}} * 100 \%$

Where; $\mathrm{V}_{\mathrm{a}}$ : The input terminal voltage (source), $(\mathrm{V})$;

$e_{b}$ : The back emf, (V);

$\mathrm{R}_{\mathrm{a}}$ : The armature circuit resistance, (ohm); $\mathrm{i}_{\mathrm{a}}$ : The armature current, (Amp);

$\mathrm{L}_{\mathrm{a}}$ : The armature inductance, $(\mathrm{H}) ; \mathrm{L}_{\mathrm{af}}$ : The field- armature mutual inductance $(\mathrm{H})$;

$\mathrm{J}$ : Moment of inertia of motor shaft. $\left(\mathrm{Kg}-\mathrm{m}^{2}\right)$;

$\mathrm{T}_{\mathrm{e}}$ : Torque produced by the motor, $(\mathrm{N}-\mathrm{m})$;

$\mathrm{T}_{\mathrm{sh}}:$ Shift torque, $(\mathrm{N}-\mathrm{m})$

$\omega_{r}:$ Rotor speed, $(\mathrm{rad} / \mathrm{s})$;

B : Viscous friction coefficient, $(\mathrm{N}-\mathrm{m} / \mathrm{rad} / \mathrm{sec})$;

$\mathrm{T}_{\mathrm{L}}$ : The load torque, (N.m);

$\mathrm{K}_{\mathrm{E}}$ : The motor constant, (V/A- rad/s).

The DC motor ratings and parameters are presented in Appendix (A). 
The developed torque $\left(\mathrm{T}_{\mathrm{e}}\right)$ is proportional to armature current ,motor flux ,as shown in equation (5).

$\mathrm{I}_{\mathrm{f}} \alpha \phi$

$\mathrm{T}_{\mathrm{e}}=\mathrm{K}_{\mathrm{t}} \mathrm{I}_{\mathrm{a}} \phi$

Where $\phi$ is flux $(\mathrm{Wb})$. There is a linear region in the magnetizing curve between flux $(\phi)$ and field current $\left(\mathrm{I}_{\mathrm{f}}\right)$,in other words ,proportional relationship .

$T_{e}=K_{t} I_{a} I_{f}$

In the armature control of DC motor which utilizes constant field current, the control system contains armature current as a feedback to indicate the load torque. Whereas, in this paper the feedback of the controller is armature current multiplied by the field current to represent the load torque as indicated by equation (14) [1].

\section{Fuzzy Logic Controller :}

The basic structure of the FLC is shown in Figure (2). The main structure units of the FLC are a fuzzification unit, a fuzzy logic reasoning unit, a knowledge base unit, and a defuzzification unit. Defuzzification is the process of converting inferred fuzzy control actions into a crisp control action[5].

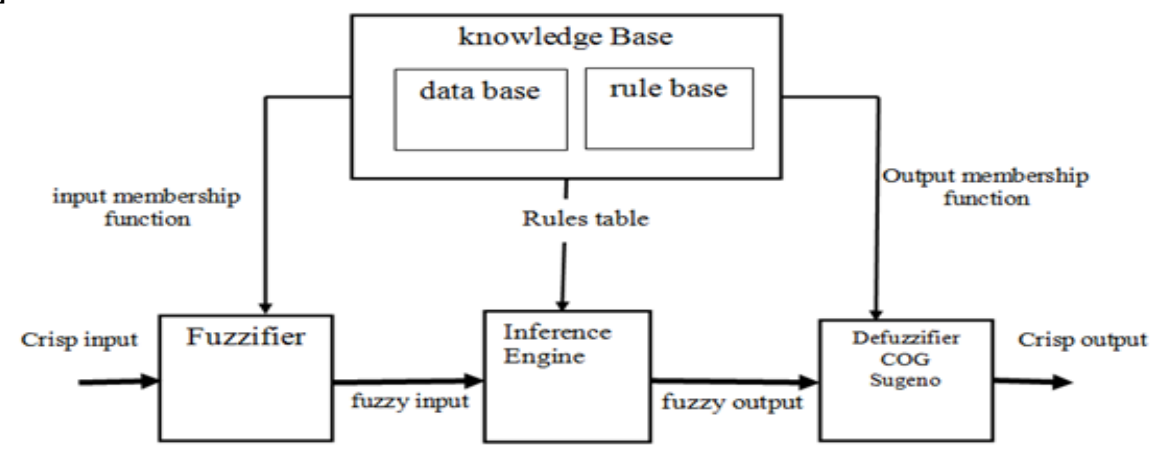

Fig .2 The Fuzzy Logic Control Structure

The fuzzy knowledge-base has a rule-base that maps a fuzzy input variable E into a fuzzy output $U$. This can be expressed by a linguistic statement which may be written as [6]:

IF $\boldsymbol{E}$ THEN $\boldsymbol{U}$. in MATLAB but in Microcontroller : DC P_E,\$FE,P_U,\$FE

The fuzzy knowledge-base also has a database defining the variables. A fuzzy variable is defined by a fuzzy set, which in turn is defined by a membership function. Fuzzy reasoning is used to infer the output contributed from each rule. The fuzzy outputs reached from each rule are aggregated and defuzzified to generate a crisp output. The core of a fuzzy logic controller is thus based on a linguistic model (the rule base and the defined membership functions)[6].

\section{Design of the Fuzzy Controller In MATLAB /Tool Box:}

In this section a comparison is presented between fuzzy controller for armature control only, and fuzzy controller for armature - field speed control of a DC motor. It should be noted that the membership functions which are used for the controller inputs are of trapezoidal type. The main reason for this selection is the ability to implement such membership function on the (MC9S12DP256B) microcontroller as it will be explained later. 


\section{A- Armature Fuzzy speed Control (AFC).}

The fuzzy controller has four inputs, and one output. The first input is the reference speed (Wref) to make the FLC know the set speed ,the second input is the speed error ,the third input is the change of speed error, and the fourth input is the armature current (Ia) that reflects the load torque to the fuzzy controller . Figure (3) shows the input fuzzy membership functions. Figure (4) represents the singleton values of the percentage duty cycle for the armature drive circuit.

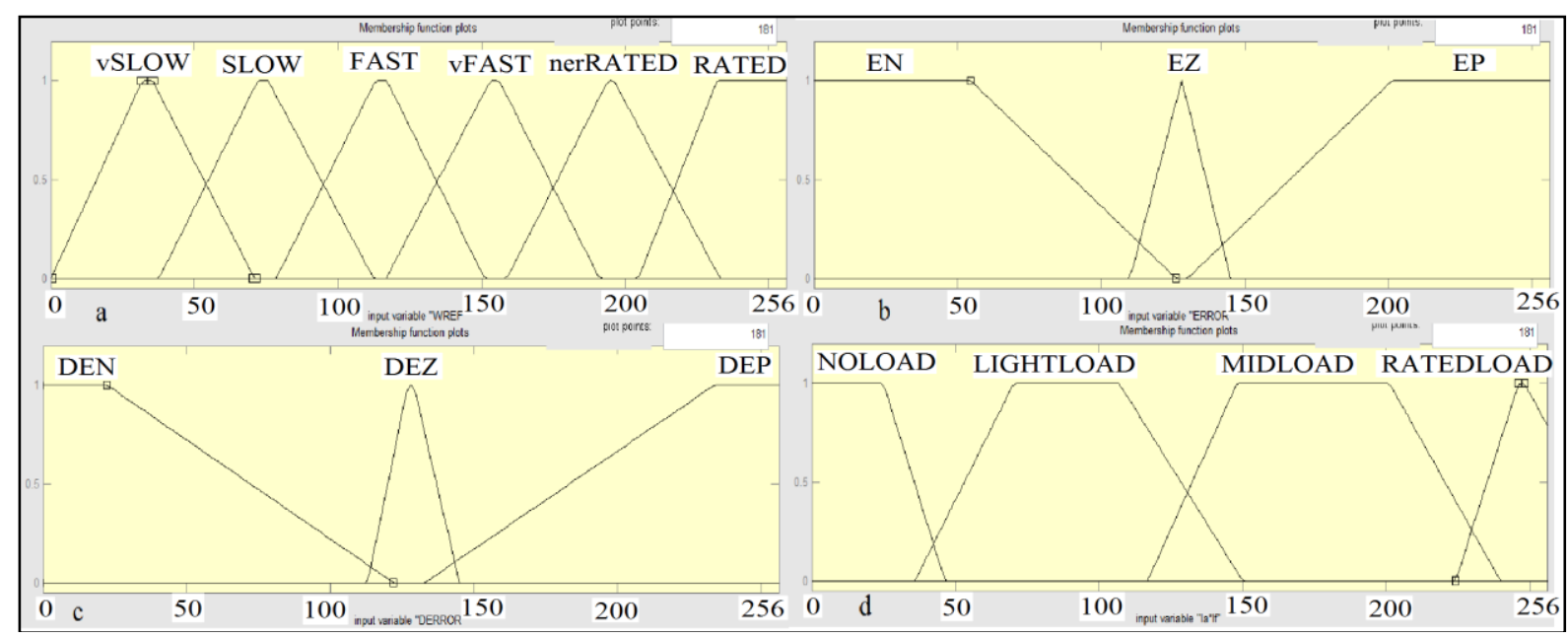

Fig. 3. Fuzzy membership function of the AFC controller inputs (a) Reference Speed (b) Speed Error(c) Change of Speed Error (d) Armature Current.

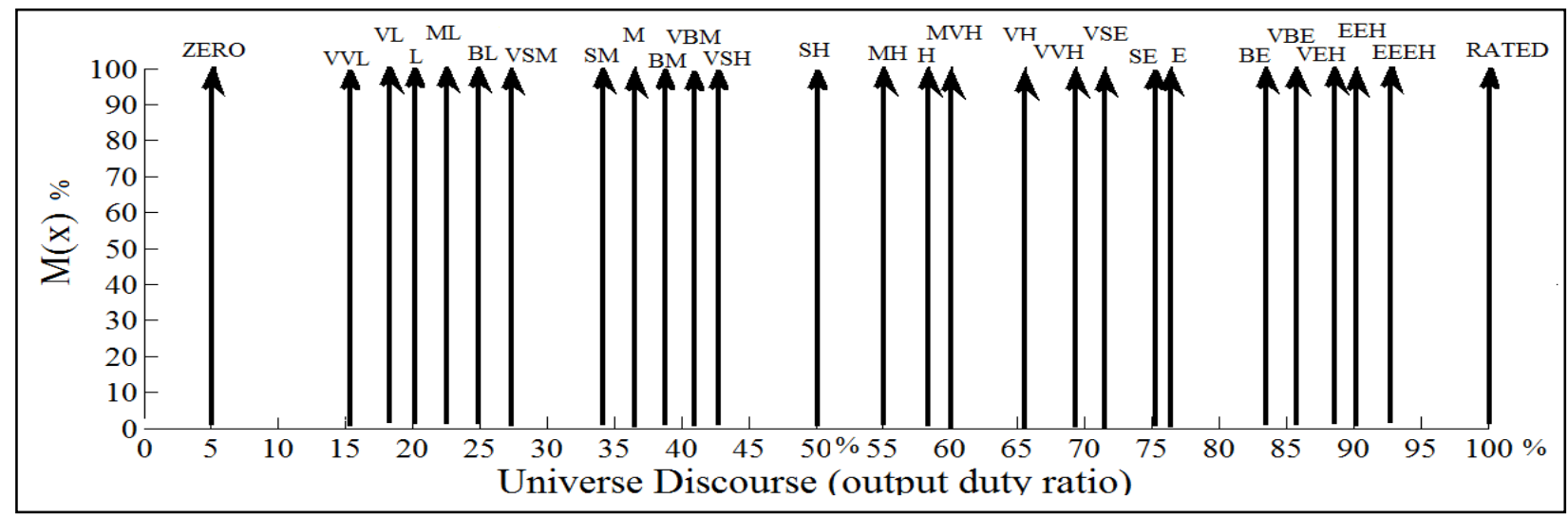

Fig.4.The singleton output membership functions for (AFC).

\section{B- Armature-Field Fuzzy speed Control (AFFC).}

In this case two variables must be controlled at the same time to get the desired speed, with increasing the motor's efficiency over the whole range of load condition as an important goal. .In this fuzzy speed controller, there are four inputs and two outputs .These inputs are; the reference speed (Wref),the speed error ,the change of speed error , and the armature current $\left(\mathrm{I}_{\mathrm{a}}\right)$ multiplied by field current $\left(\mathrm{I}_{\mathrm{f}}\right)$ as a feedback signal representing the load torque. The controller outputs are the percentage duty cycle for the armature and field drive circuits. Figure (5) shows the designed 
fuzzy membership function of the controller inputs. Figure (6)and (7) represents the singleton values of the percentage duty cycle for the armature and field drive circuits, respectively.

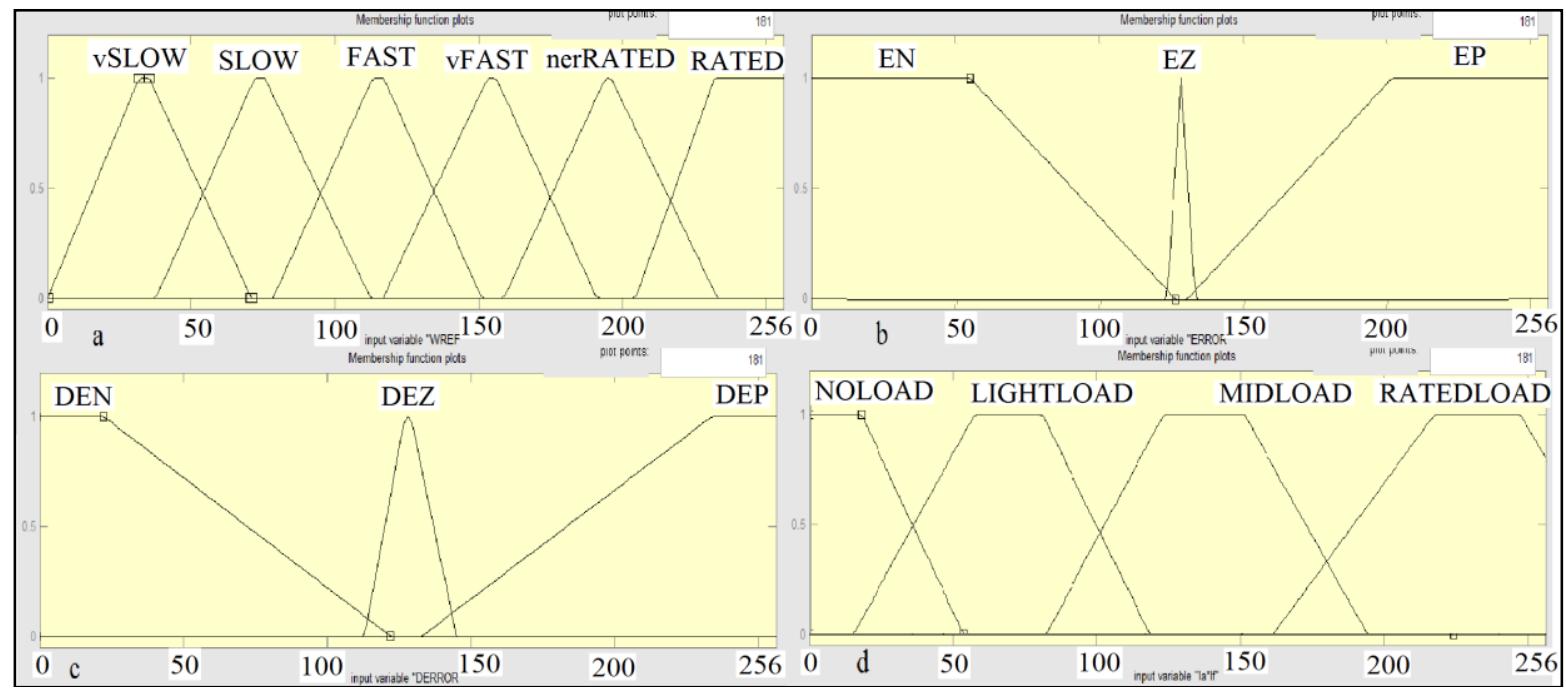

Fig. 5. Fuzzy membership function of the AFFC controller inputs (a) Reference Speed (b) Speed Error (c) Change of Speed Error (d) Armature Current multiplied by field current.

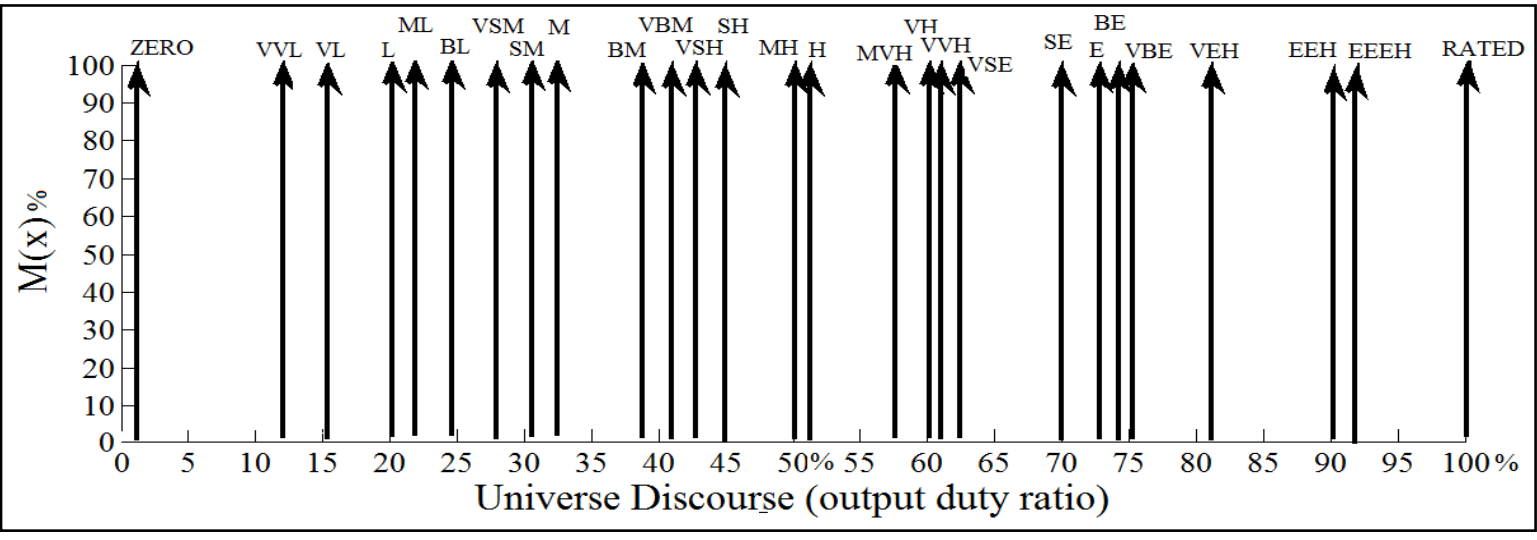

Fig.6. The Armature voltage singleton output membership functions for (AFFC).

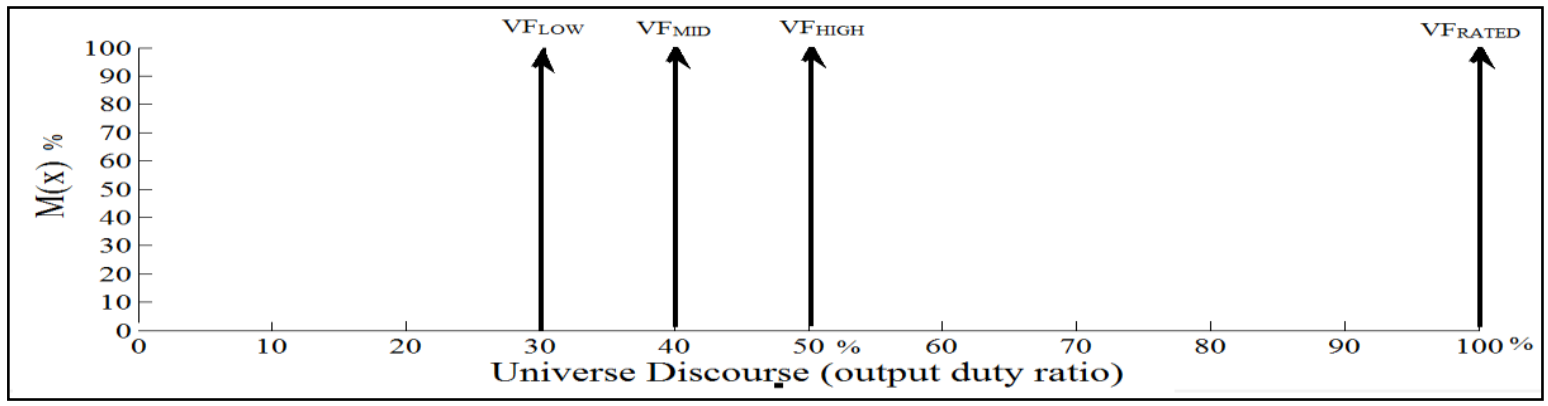

Fig.7. The Field voltage singleton outbut membershin functions for (AFFC). 


\section{Overall System Design using MATLAB :}

The designed system in MATLAB is used to investigate the performance of the fuzzy controller and the improvement of the dc motor efficiency. The efficiency calculation blocks are shown in Figure (8) based on equation (11). Figure (9) shows the system with fuzzy controller together with the components of the simulated system which are; DC motor, DC-DC converter (Choppers buck circuits), pulse generators, voltmeters, ampere meters.

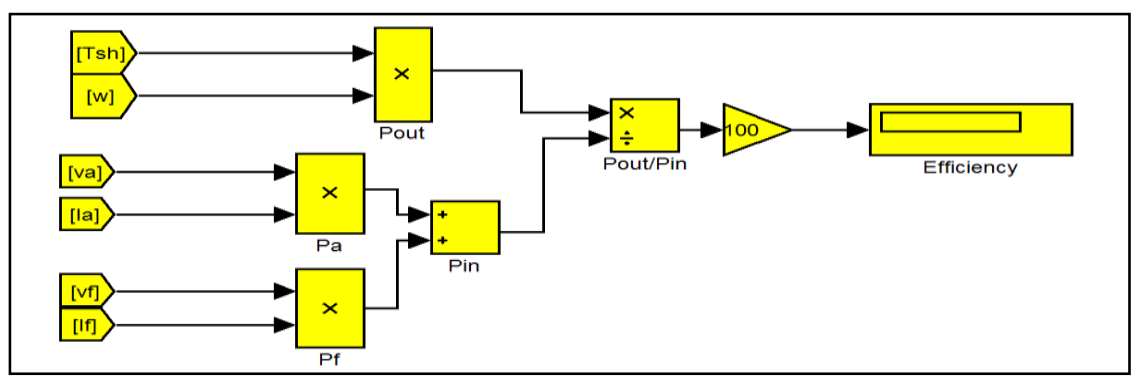

Fig .8 DC motor efficiencv calculation blocks

Here the fuzzy controller has two goals, the first one is speed regulation and the second is the efficiency improvement.

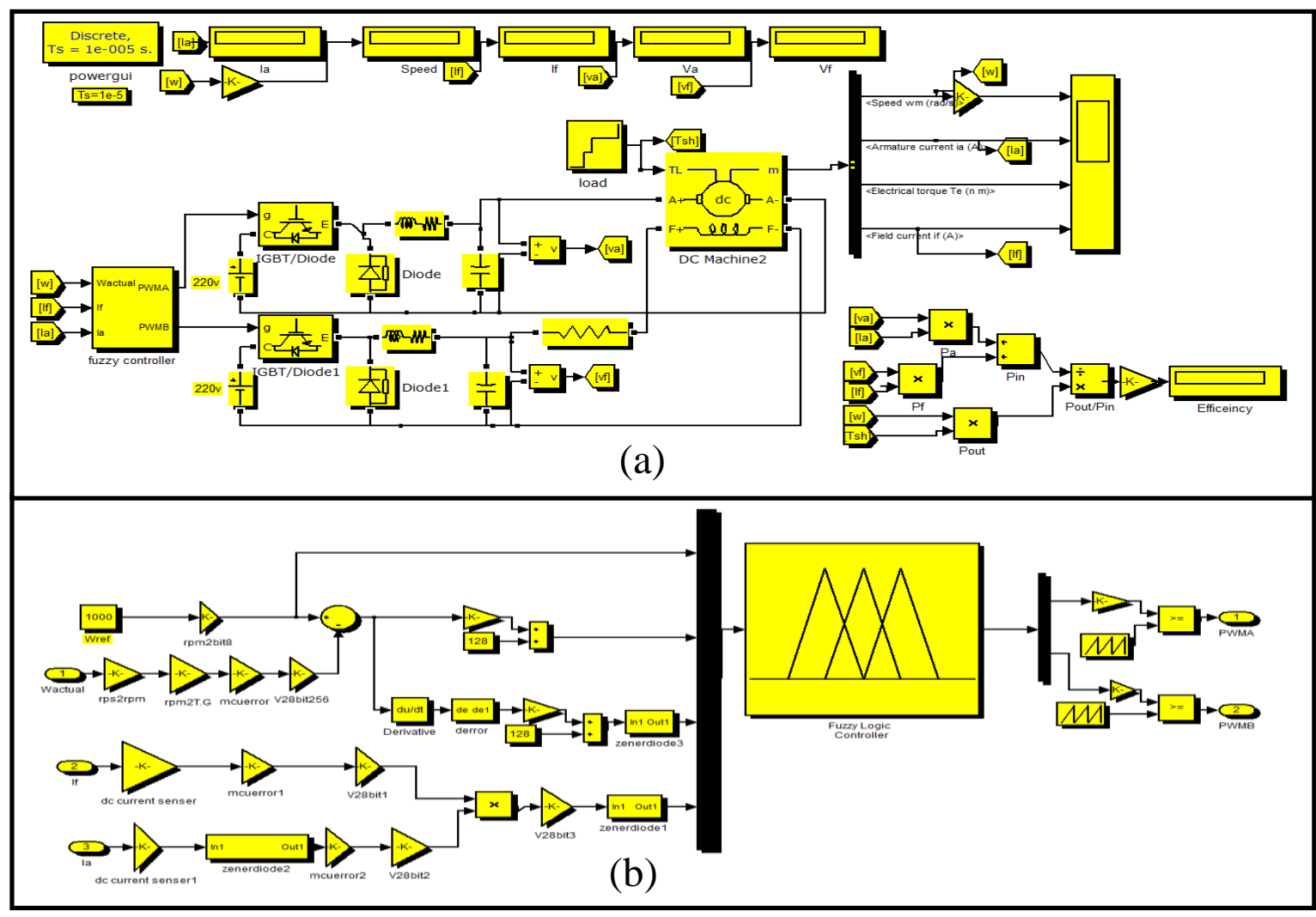

Fig .9 :(a) overall system design using MATLAB (b) fuzzy controller 


\section{Practical Design Of The Overall System with (AFFC):}

The AFC and the AFFC are implemented using microcontroller type (MC9S12DP256B). The main reason for selection this type of controller is the availability of ready-made programmed instructions that perform nearly all fuzzy operations (MEM, WAV, REV... etc). Furthermore, it is simple to program, load, erase, change variables throughout PC interface, and fast (125 nSec./cycle). The block diagram of the overall practical system is shown in Figure (10). There are three inputs to microcontroller; the first is the motor speed signal which is coming from the taco generator, the second is the armature current, and the last is the field current .Inside the microcontroller a subprogram was built to produce the error of speed and the rate of change of this error. Another subprogram was built to multiply the armature current by the field current. The outputs of the fuzzy controller are the percentage duty cycles for the armature Buck circuits and for the field Buck circuit. Indeed, for comparison purposes, the same membership functions for input and output variables which are used in section (4) are utilized here. The experimental system components are shown in Figure (11) and the algorithms flowchart embedded in the MC9S12DP256B microcontroller is shown in Figure (12).

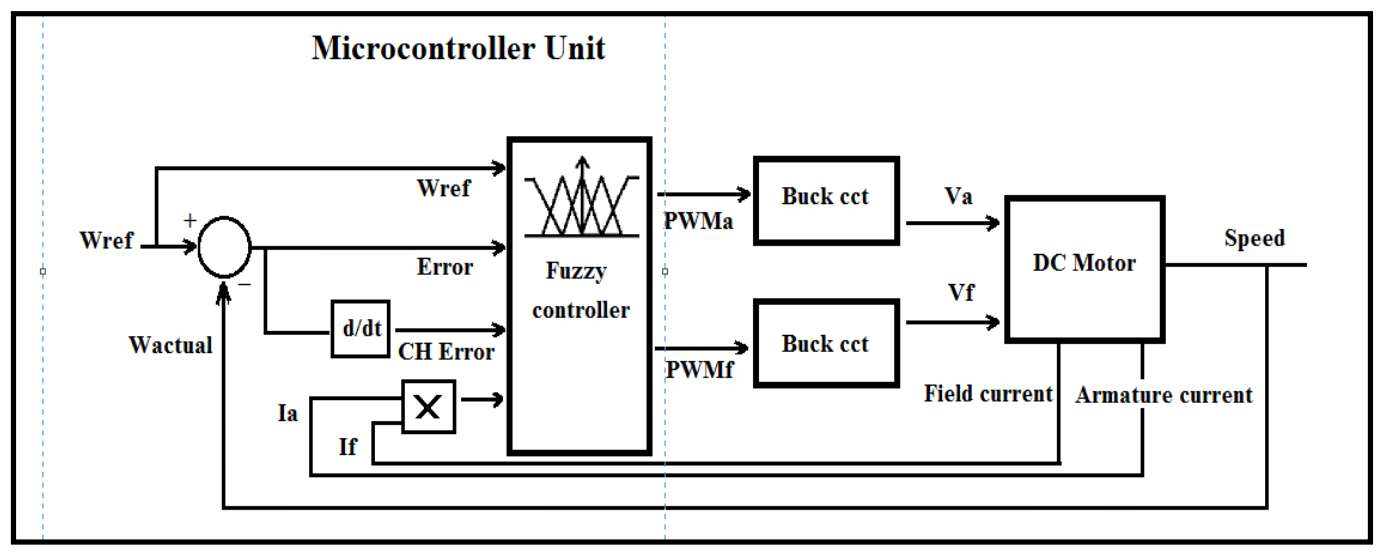

Fig.10 Block diagram of the experimental designed system (AFFC)

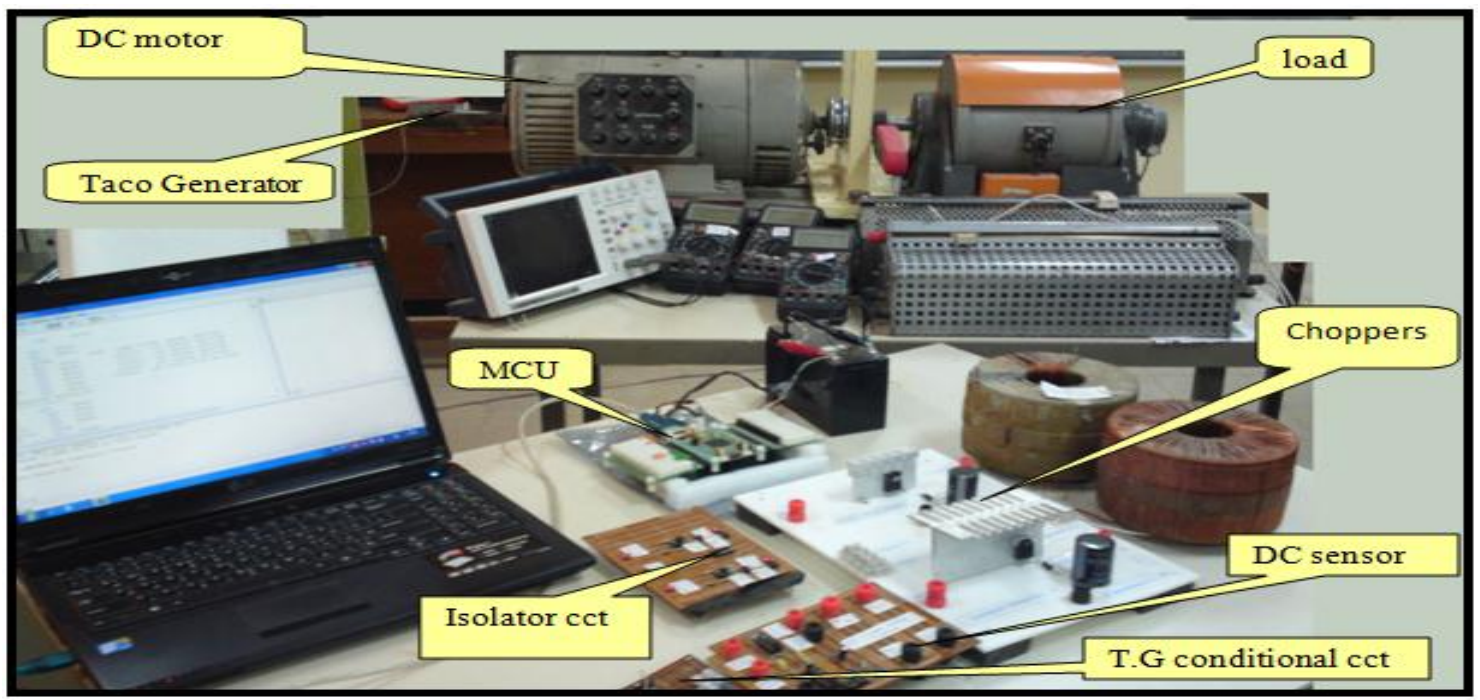

Fig.11 System components 


\section{Programming strategy employed in this work :}

A microcontroller-based fuzzy logic control system has two parts. The first part is a fuzzy inference kernel which is executed periodically to determine system outputs based on current system inputs. The second part of the system is a knowledge base which contains membership functions and rules. Figure (12 (a)) is a block diagram of this kind of fuzzy logic system. Figure (12 (b)) is a fuzzy inference kernel can be written by a programmer who does not know how the application system works. The knowledge base can be developed by an application expert without any microcontroller programming experience. Membership functions are simply expressions of the expert's understanding of the linguistic terms that describe the system to be controlled. Rules are ordinary language statements that describe the actions a human expert would take to solve the application problem.

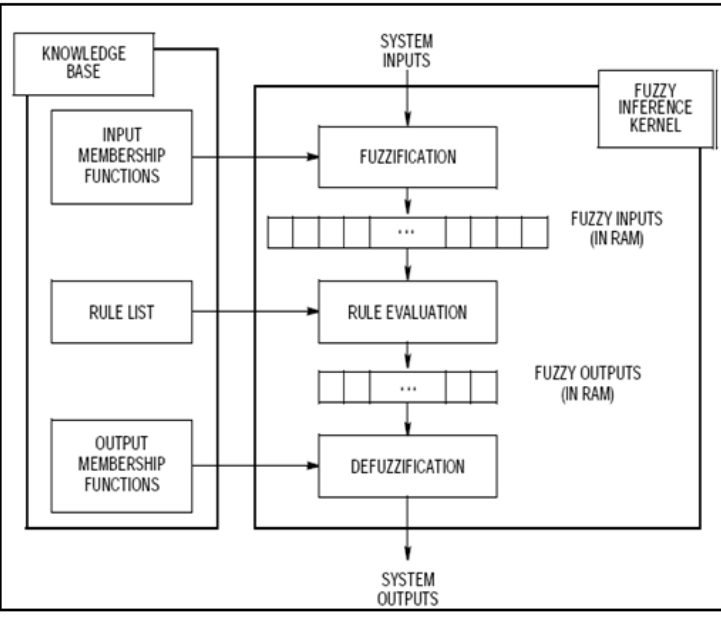

(a)

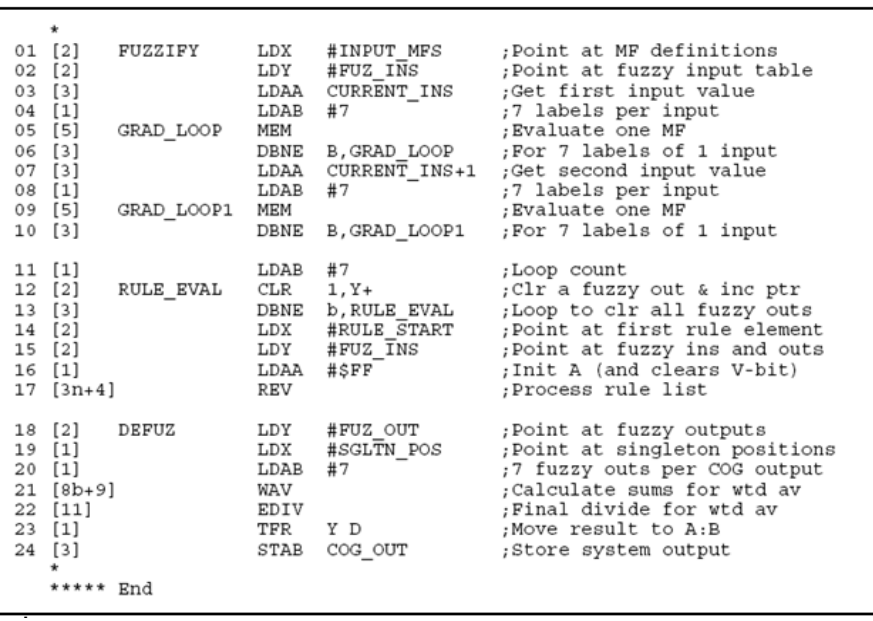

(b)

Fig.12. (a) Block diagram of a fuzzy logic system. (b) Typical example Fuzzy inference

The only thing the programmer needs to do with knowledge base information is to store it in the memory locations used by the kernel. One execution passing through the fuzzy inference kernel generates system output signals in response to current input conditions. The kernel is executed as often as needed to maintain control .Figure (13) shows the flow chart of the implemented fuzzy logic program

Fig.13.Flow chart of the main program of the fuzzy controller

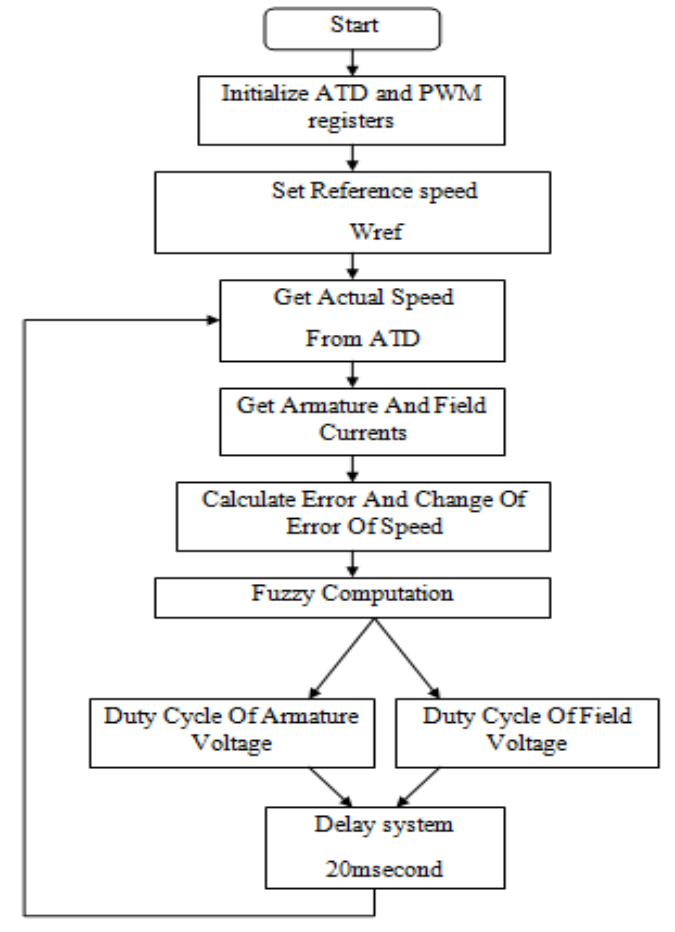




\section{Simulation Results:}

A comparative simulation results are presented for the two cases:

a. Armature Fuzzy speed Control (AFC).

b. Armature-Field Fuzzy speed Control (AFFC).

Figure (14) and Figure (17) illustrate the step response of initially loaded motor by $25 \%$ of the rated load and then remove it suddenly under AFC and AFFC algorithms, respectively. The corresponding armature and field currents are shown in Figures (15and (18). Finally, the motor step responses from standstill to500 rpm and then to $1000 \mathrm{rpm}$ are illustrated in Figures (16) and (19) under AFC and AFFC algorithms, respectively.

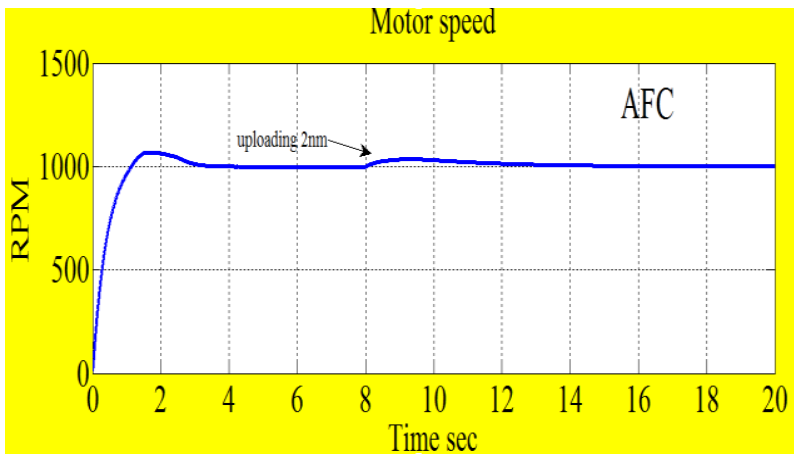

Fig.14 speed response at ref 1000rpm and uploading

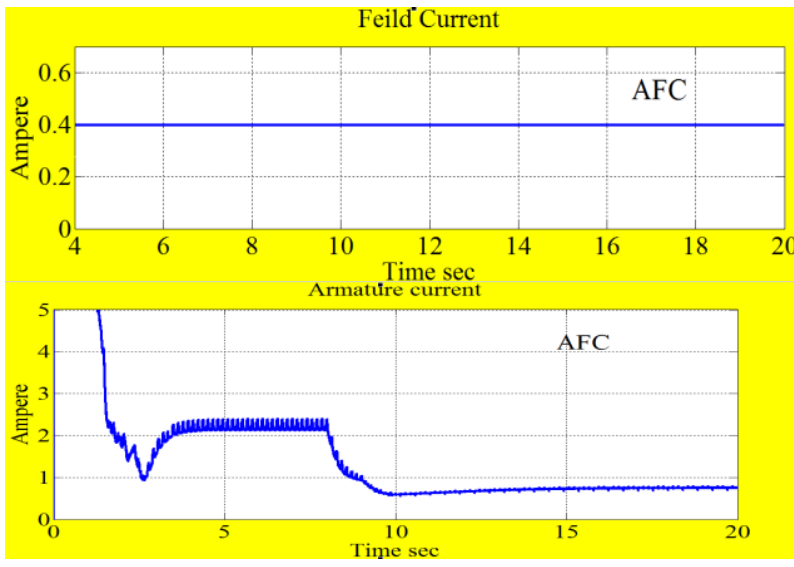

Fig.15 Field and Armature currents at uploading step

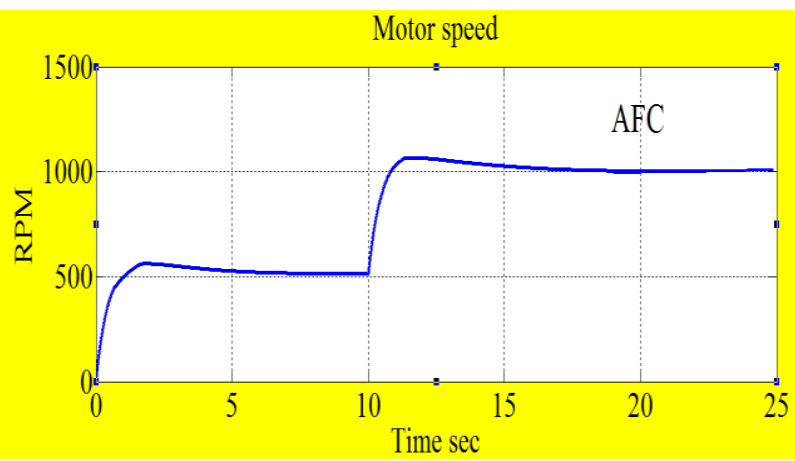

Fig.16 Motor Speed Response From 500to 1000rpm

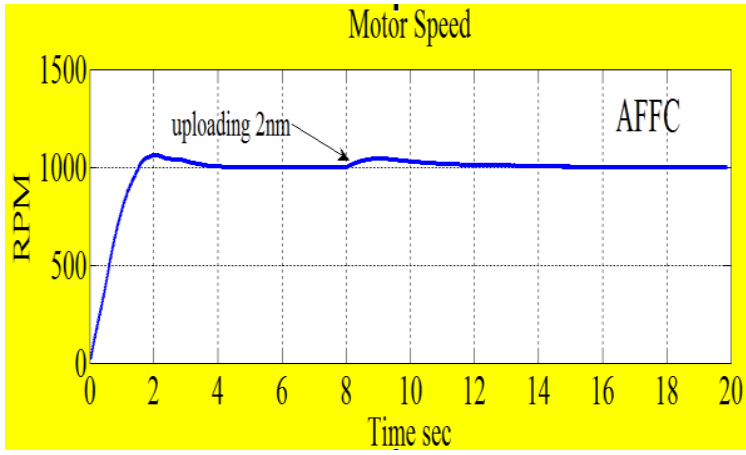

Fig.17 speed response at ref 1000rpm and uploading
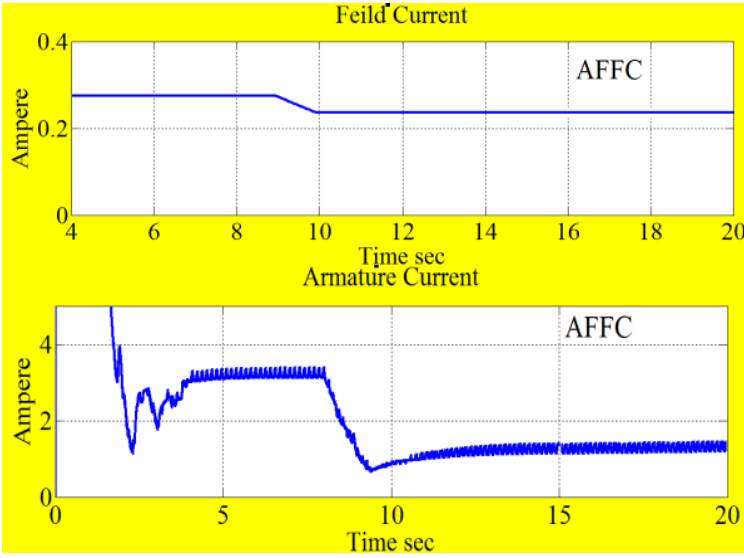

Fig.18 Field and Armature currents at uploading step

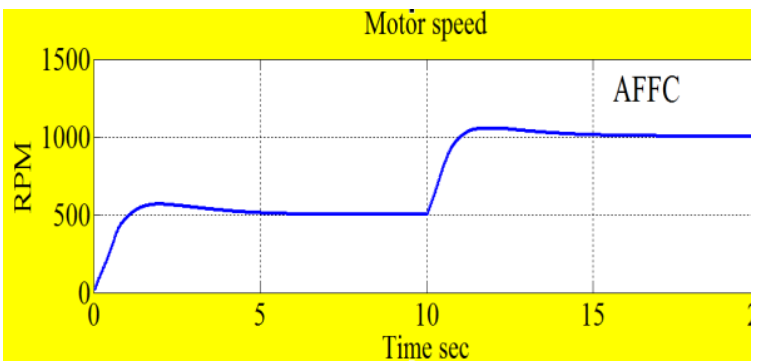

Fig.19 Motor Speed Response From 500to 1000rpm 


\section{Experimental Results:}

To validate the simulation results, the same tests are performed practically under AFC and AFFC algorithms. Figure (20) and Figure (23) illustrate the step response of initially loaded motor by $25 \%$ of the rated load and then remove it suddenly under AFC and AFFC algorithms, respectively. The corresponding armature and field currents are shown in Figures (21 and (24). Finally, the motor step responses from $500 \mathrm{rpm}$ to $1000 \mathrm{rpm}$ are illustrated in Figures (22) and (25) under AFC and AFFC algorithms, respectively.

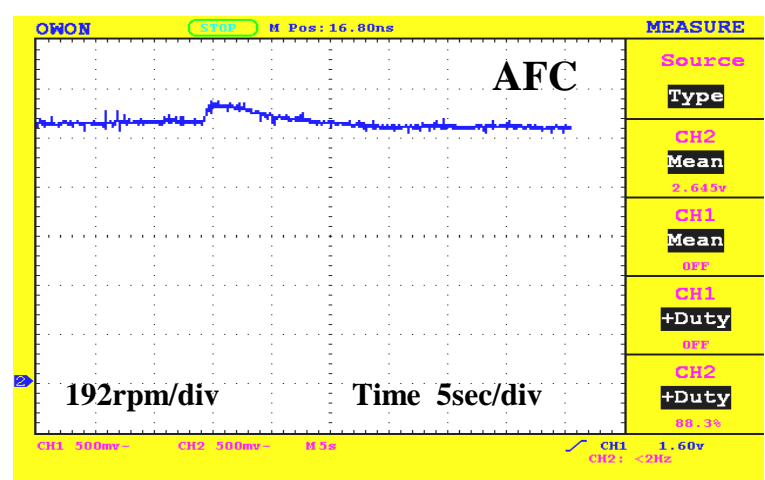

Fig.20 speed response at ref 1000rpm ,uploading

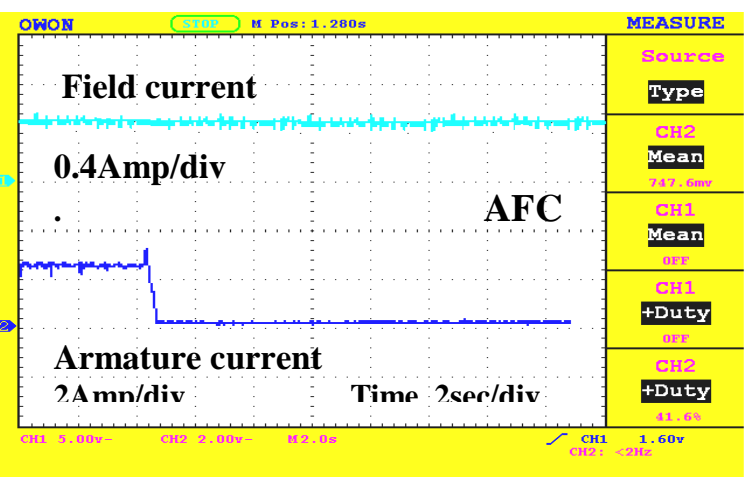

Fig.21 Armature and Field currents when uploading at1000rpm

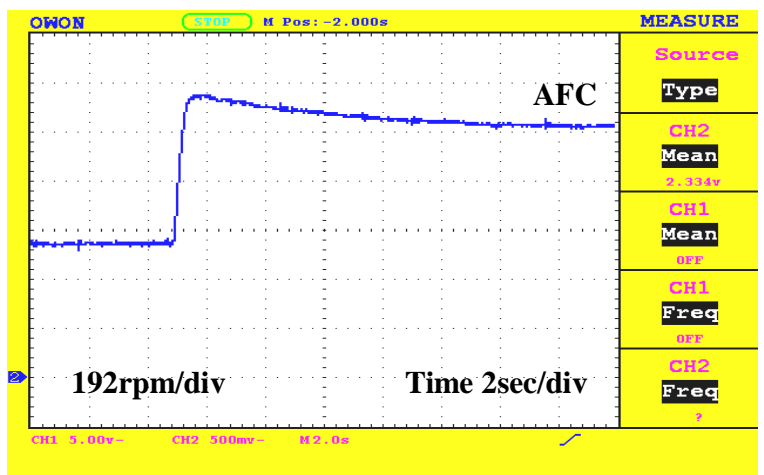

Fig.22 Motor Speed Response From 500to 1000rpm

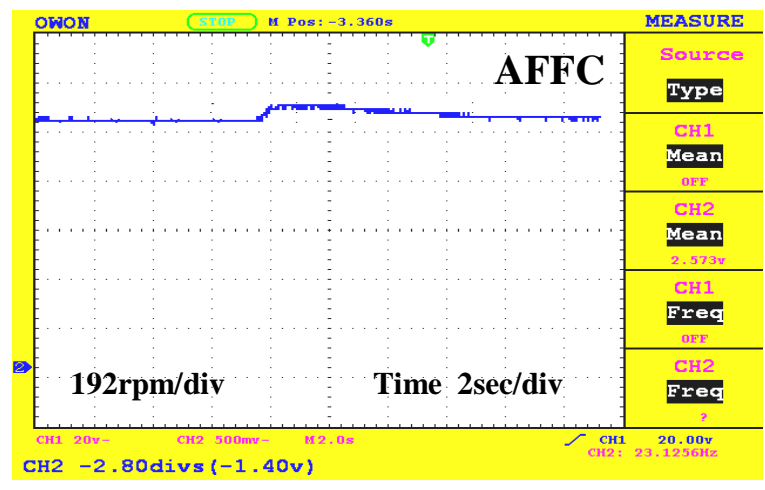

Fig.23 speed response at ref 1000rpm ,uploading

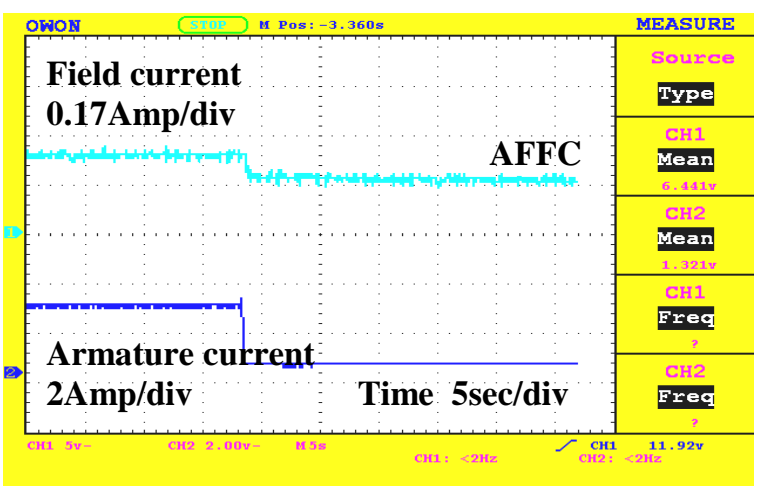

Fig.24 Armature and Field currents when uploading

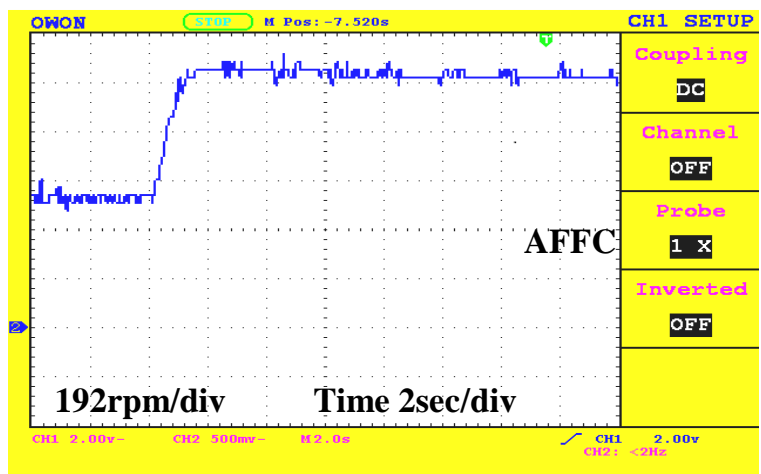

Fig.25 Motor Speed Response From 500to 1000rpm 


\section{CONCLUSIONS :}

The main features of the FLC are; its non-linear characteristics and its capability to act as a decision maker in dealing with its input variables. Such important two features are fully exploited in this paper to design and implement a FLC that control both the DC motor armature voltage and the field voltage ( in sequence, the field current) to regulate its speed. This goal is achieved under condition of motor efficiency improvement in comparison to the well-known speed control method that relies on varying the armature voltage only and keeps the field current at rated value.

However one can highlight the following concluding points:

1. The speed of the separately excited DC motor was controlled by fuzzy logic controller facing unknown and variable load torque (speed regulation and disturbance rejection)

2. The FLC rules are selected in a way that noticeably increases the efficiency of the motor in the light and medium load conditions as shown in Figures (26) and (27). As indicated in Table (1), the efficiency is improved by nearly $5 \%$ at $25 \%$ load and (1.7\%-1.9\%) at 50\% load over different values of regulated speed.

3. Indeed, this proposed technique causes an increase in hardware efforts due to need of two drivers to supply the necessary armature voltage and field current, three feedback signals, two current sensors, and two isolator circuits. However, such techniques would be more valuable in the context of enhancing the efficiency especially for high rated motors (above $5 \mathrm{~kW})$.

Table (1) efficiency enhancement

\begin{tabular}{|c|c|c|}
\hline $\begin{array}{c}\text { Motor } \\
\text { Speed }\end{array}$ & Load\% & $\begin{array}{c}\text { Efficiency } \\
\text { improvement }\end{array}$ \\
\hline \multirow{3}{*}{$\begin{array}{c}750 \\
\text { RPM }\end{array}$} & $10 \%$ & $11 \%$ \\
\cline { 2 - 3 } & $25 \%$ & $5.2 \%$ \\
\cline { 2 - 3 } & $50 \%$ & $1.9 \%$ \\
\hline \multirow{3}{*}{1000} & $60 \%$ & $1 \%$ \\
\cline { 2 - 3 } RPM & $10 \%$ & $10 \%$ \\
\cline { 2 - 3 } & $25 \%$ & $5.1 \%$ \\
\cline { 2 - 3 } & $50 \%$ & $1.7 \%$ \\
\hline
\end{tabular}

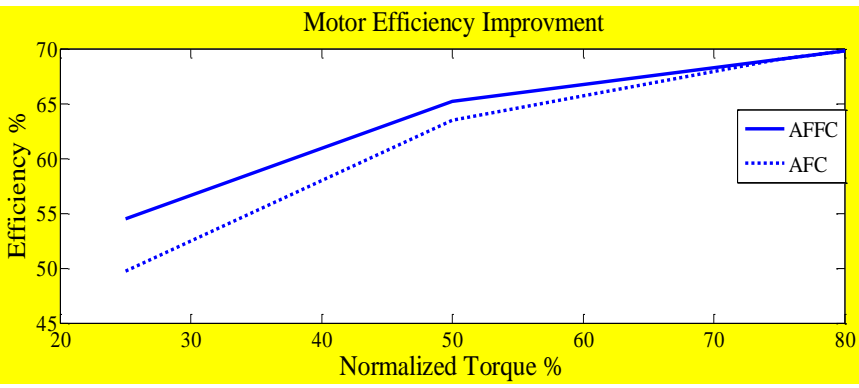

Fig.26 Motor efficiency improvement by proposed fuzzy controller at motor speed 1000rpm

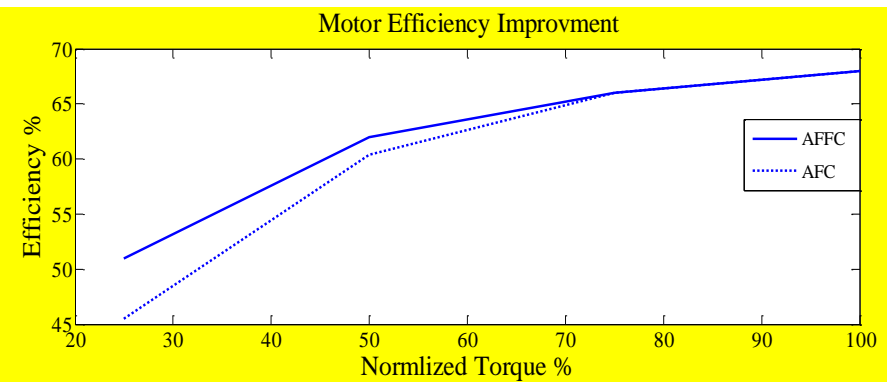

Fig.27 Motor efficiency improvement by proposed fuzzy controller at motor speed 750rpm 


\section{References:}

[1]: T. Egami, H .Morita, T .Tsuchiya, "Efficiency Optimized Model Reference Adaptive Control System For A Dc Motor,"IEEE Trans. On Industrial Electronics, Vol.37, No.1, pp.28-33, 1990.

[2]: J. Gordon Kettleborough, R. Smith, Vinod V. Vadher, Fernando L. M. Antunes “ Micro processor -Based DC Motor Drive with Spillover Field Weakening” IEEE Trans. On Industrial Electronics, Vol.38, No.6,pp.469-475,Dec, 1991.

[3]: Salah E. Gaber, Hasan A. Yousef "Efficiency Optimized Speed Control Of D.C. Motors Based On Self Tuning Regulator" IEEE, pp:385-395, 1993.

[4]: A.A. El-sattar S.Wahsh A.M. Zaki S.I.Amer "Efficiency-Optimized Speed Control System for a Separately - Excited DC Motor" IEEE Trans,pp:417-422, 1995.

[5]: A1 Jackson"A New Microcontroller with Fuzzy Inference Instructions Simplifies Controller Designs" IEEE, pp: 491-503, 1997.

[6]: Y. Tipsuwan, Y. Chow, "Fuzzy Logic Microcontroller Implementation for DC Motor Speed Control", IEEE Trans, pp. 1271-1276,USA, 1999.

[7]: Othman, Mazin Z." Practical Auto-Tuning Expert Fuzzy system for Digitally Controlled Drives" Gulf University Scientific Magazine, Vol.1, No.3, 2009, Kinkdom of Bahrain.

[8]: R.Nagaraj, P.S.Mayurappriyan, Jovitha Jerome "Microcontroller Based Fuzzy Logic Technique for DC-DC Converter" India International Conference on Power Electronics,pp:355-359, 2006.

[9]: Gaddam Mallesham, K.B. Venkata Ramana "Improvement in Dynamic Response of Electrical Machines with PID and Fuzzy Logic Based Controllers", IEEE Trans, WCECS, pp. 978-988, October 24-26, San Francisco, USA, 2007.

Appendix A

Motor Ratings and Parameters

\begin{tabular}{|c|c|c|c|}
\hline \multicolumn{2}{|c|}{ Motor ratings } & \multicolumn{2}{|c|}{ Motor parameter } \\
\hline $\mathbf{P}$ & $1.3 \mathrm{~kW}$ & Element & Value \\
\hline $\mathbf{V}_{\mathbf{a}}$ & $220 \mathrm{~V}$ & $\mathbf{R}_{\mathrm{a}}$ & $2.7 \Omega$ \\
\hline Torque & $8.1 \mathrm{NM}$ & $\overline{\mathbf{L}_{\mathbf{a}}}$ & 39mH \\
\hline $\mathbf{I}_{\mathrm{a}}$ & 7.3A & $\mathbf{R}_{\mathbf{f}}$ & $485 \Omega$ \\
\hline $\mathbf{V}_{\mathrm{f}}$ & $220 \mathrm{~V}$ & $\mathbf{L}_{\mathbf{f}}$ & $8.2 \mathrm{H}$ \\
\hline $\mathbf{I}_{\mathbf{f}}$ & $0.4 \mathrm{~A}$ & & \\
\hline $\mathbf{N}$ & 1500rpm & & \\
\hline
\end{tabular}

The work was carried out at the college of Electronics Engineering. University of Mosul 